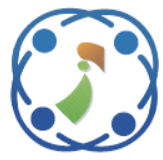

\title{
Spatial Data Modeling on GIS for Classification of Measles-prone Region Using Multiple Attribute Decision Making
}

\author{
Anik Vega Vitianingsih $^{1 *}$ Achmad Choiron $^{1}$ Dwi Cahyono $^{1}$ Azizul Umam $^{1}$ Suyanto Suyanto ${ }^{2}$ \\ ${ }^{1}$ Informatics Departments, Universitas Dr. Soetomo Surabaya, Indonesia \\ ${ }^{2}$ Economic and Bussiness Faculty, Universitas Dr. Soetomo Surabaya, Indonesia \\ *Corresponding author E-mail: vega@unitomo.ac.id
}

\begin{abstract}
Indonesia is a country that has a tropical climate, so that many typical tropical climate diseases emerge. This disease is caused by viruses and parasites that breed during the dry season or the rainy season. One typical tropical disease is measles. This paper discusses the geographical information system (GIS) technology by analyzing spatial data modeling to determine the classification of measles-prone areas based on immunization status coverage using the Simple Additive Weighting (SAW) and Weight Product Model (WPM) method. Some parameters are used consist of immunization status data for multiple attribute decision making (MADM), diseases preventable by immunization (PD3I), epidemic and nutritional status of infants. The SAW and WPM method in modeling spatial data analysis processes data according to the parameters to determine the scale in comparing all alternative data on the scope of classification of immunization status areas, namely: good, average, fair and poor. The test results with the Cohen's Kappa Method Consistency Test (MCT) is obtained an average coefficient of 0.41 for consistent measurements for the chosen method. It can be concluded that the two measurements using the SAW and WPM methods have a moderate for the strength of agreement category, for using in spatial data modeling on the GIS for classification of measles prone regions using MADM.
\end{abstract}

Keywords: GIS, Spatial data modeling, MADM, SAW, WPM, Cohen's Kappa, Tropical diseases, Measles.

\section{Introduction}

Measles is one of the diseases that often becomes an extraordinary event in the tropics, such as Indonesia. The spread of measles is a global problem in the health sector. The problems, information on the incidence of measles is still based on risk factors for immunization status in the measles surveillance technique manual. Research studies are still descriptive statistics and there are no system applications that globally can identify areas prone to measles disease based on multi-criteria parameters to determine the distribution of vulnerable categories of regions. Measles control in this decade has been done by giving complete immunization to every baby or child, as a mitigation measure by the public health authority [1], measles is one type of disease that breeds in regions with tropical climates [2]. Based on the World Health Organization (WHO), measles incidence rate per million, Indonesia is a country with 6345 cases at a rate of 24.30. In 2017 the number of confirmed 11389 cases increased compared to 2016 which only reached 7204 confirmed cases [3]. Spatial patterns can be used to identify patterns of behavior of measles spreading, based on local seasonal factors in each region [4].

In the beginning, spatial data modeling was done by analyzing the needs of geospatial data to be processed for decision-making systems. The need for spatial data analysis was important in the field of research and policy making, provides a description of data needs, methods, and illustrations of case studies used [5], as well as in the health sector [6,7] measles field [8]. Analysis of spatial data as a mitigation measure for disease prevention and control had a very important role. This was developed based on the conditions of regional climate and social behavior of the community, the method of Inverse Distance 
Weighting (IDW), the functions and weighted overlay functions were used to predict the location of disease spread [9]. The risk of spreading the disease to areas adjacent to the affected area has been carried out by using a spatial clustering method. In this method, a comparison was made on spatial grouping in heterogeneity. The resulting information would be beneficial for the Ministry of Health to formulate regional coping strategies as hotspots in epidemic diseases [10].

Spatial data modeling was the process of spatial analysis results data to determine the decisions and policies of stakeholders. The resulting process included geocoding and mapping to produce a decision-making system $[11,12]$ through the application of artificial intelligence (AI) methods [13]. The AI method used to map measles has been applied including fuzzy inference system [14], Data mining techniques [15], Bayesian mixture model [16], hierarchical Bayesian model [17], Bayesian spatial modeling [18]. The AI fuzzy inference system method is used to determine the symptoms of measles based on the input variable rule in the inference engine [14]. Artificial Neural Network (ANN), Decision Tree Algorithm and Naïve Bayes Classifier on Data Mining techniques, are used to predict disease trends. One of them is measles based on time series database disease [15]. Bayesian Normal mixture models were used to estimate the prevalence of measles through age factor [16]. Spatial hierarchical Bayesian models are used to map the risk of measles based on data on the number of measles, unemployment, birth rates, education level and age of immunization [17]. Bayesian spatial modeling is used to determine the mapping of disease populations based on disease statistics [18].

According to previous research, geographical information system (GIS) technology was utilized through spatial analysis to identify groups of low or high for measles, mumps and rubella (MMR) immunization levels with spatial, temporal and spatial-temporal methods [19]. Bayesian regression spatial model was used to identify the risk of measles spread at the regional level using data series in 20052014, the results obtained indicate the parameters of birth rate, number of measles cases, unemployment rate and the proportion of children immunized at 12 months to be a determinant in prevention of measles [17]. Socio-economic disparity had become a separate problem in the success of measles immunization programs, using multiple spatial regression methods mapping is done to identify the distribution of immunization coverage based on socio-economic inequality. This was a step in mitigating the spread of measles virus [20]. Web- based GIS technology was developed as a web-based health surveillance system [21]. However, the research that has been done has not used the approach and parameters that would be proposed in the discussion of this paper, that is, with a multi-criteria parameter approach to explore the need for supporting factors in the analysis process, interview experts in the field of disease prevention and control of the Indonesian East Java Provincial Health Office, and analyze the behavior of data to determine AI methods through mathematical modeling that is suitable for producing distribution multi-class classification vulnerable area. The results of measles data processing based on the AI method are still presented in graphical form [14-16], Multi-criteria parameters that will be proposed for spatial data modeling with SAW and WPM methods in the discussion of this paper, have not been used in previous studies $[17,18]$.

The purpose of this paper was to propose an approach through spatial data modeling to determine the distribution of measles-prone areas based on immunization status coverage. Multiple attribute decision making (MADM) was used in the modeling of spatial data because alternative results in regional coverage use multi-parameter criteria including diseases preventable by immunization (PD3I), epidemic and nutritional status of infants taken from basic data on the health profile book of East Java Province of Indonesia in 2011-2016 obtained at the regional level [22-27]. The multi-class classification was obtained from the results of spatial data modeling using the Simple Additive Weighting (SAW) and Weight Product Model (WPM) method in the form of immunization status coverage: good, average, fair, and poor.

The spatial analysis produced spatial data modeling which was used to determine relationship between the basic data to be processed, with the parameters used as a factor of an area categorized in the classification of measles-prone areas based on immunization status coverage. Analysis and design of the built system have been described in advance according to the needs of spatial data that would be processed to become modeling [28].

The results of the spatial data modeling with the SAW method and WPM method obtained the preference value using The Guttman Scale Assessment. The alternative good category on the SAW method if the $V_{i}$ preference value is above 0,875 , the average category with the $V_{i}$ preference value between 0,75 to 0,875 , the $V_{i}$ preference value between 0,625 to 0.75 for the fair alternative category, and poor for the preference $V_{i}$ below 0,625. The 
Table 1. Description of the multi-criteria parameter spatial datasets measles diseases

\begin{tabular}{|c|c|c|c|c|c|}
\hline $\begin{array}{c}\text { Spatial } \\
\text { Datasets }\end{array}$ & $\begin{array}{l}\text { The Priority } \\
\text { Value }\end{array}$ & Weight & $\begin{array}{c}\text { Incidence rate } \\
\text { (annually) }\end{array}$ & Category of PD3I & $\begin{array}{c}\text { Level of } \\
\text { importance }\end{array}$ \\
\hline \multirow[t]{2}{*}{ PD3I } & \multirow[t]{2}{*}{2} & \multirow[t]{2}{*}{0.30} & PD3I >12 months a year & Poor & 1 \\
\hline & & & PD3I $<12$ months a year & Good & 2 \\
\hline \multirow[t]{3}{*}{ Epidemic } & \multirow[t]{3}{*}{3} & \multirow[t]{3}{*}{0.15} & Epidemic $>60$ cases a year & Poor & 1 \\
\hline & & & Epidemic $<60$ cases a year & Good & 2 \\
\hline & & & Epidemic $=0$ cases a year & Very good & 3 \\
\hline $\begin{array}{c}\text { Spatial } \\
\text { Datasets }\end{array}$ & $\begin{array}{c}\text { Value of the } \\
\text { priority }\end{array}$ & Weight & The status & $\begin{array}{c}\text { Range } \\
\text { Standard Deviation (sd) } \\
\end{array}$ & $\begin{array}{c}\text { Level of } \\
\text { importance }\end{array}$ \\
\hline \multirow{4}{*}{$\begin{array}{c}\text { Nutrition } \\
\text { Status }\end{array}$} & \multirow[t]{4}{*}{4} & \multirow[t]{4}{*}{0.10} & Very good nutrition & $\mathrm{sd} \geq 2$ & 4 \\
\hline & & & Good nutrition & $\mathrm{sd}<2 \& \& \mathrm{sd} \geq-2$ & 3 \\
\hline & & & Less of nutrition & $\mathrm{sd}<-2 \& \& \mathrm{sd} \geq-3$ & 2 \\
\hline & & & Poor nutrition & $\mathrm{sd}<-3$ & 1 \\
\hline \multirow{3}{*}{$\begin{array}{c}\text { Infant } \\
\text { Immunization } \\
\text { (IM) }\end{array}$} & \multirow[t]{3}{*}{1} & \multirow[t]{3}{*}{0.45} & Good immunization & $\mathrm{IM}>90 \%$ & 3 \\
\hline & & & Average immunization & $\mathrm{IM} \leq 90 \% \& \& \mathrm{IM} \geq 80 \%$ & 2 \\
\hline & & & Fair immunization & $\mathrm{IM}<80 \%$ & 1 \\
\hline
\end{tabular}

Guttman Scale Assessment in the WPM method that is if the vector value $V_{i}$ more than 0,001488 for good category, an average category for value $V_{i}$ between 1,001274 to 0,001488 , the value of $V_{i} 0,00106$ to 0,001274 for the value category $V_{i}$ and smaller value than $V_{i} 0,00106$ for the poor category.

The results of trials which conducted on data layer (*.shp) coverage each district for the 657 subdistrict the East Java Province of Indonesia using the SAW method and WPM method for 2011-2016 data. Mapping the areas prone to measles by the SAW method, for the good category obtained 449, 488, 423, 442,409 , and 432 regions, the average category was obtained $113,79,94,134,108$, and 134 regions, the fair category was $82,56,117,69,125$, and 77 regions, and the poor category obtained $13,34,23,12,15$, and 14 regions, respectively. In the WPM method, the results of mapping for regions with good categories were $299,531,494,299,306$, and 315 , the average category was $340,92,140,337,333$, and 324 regions. from $12,7,13,8,5$, and 5 , and 6, 27, 10, 13, 13, and 13 in the number of regions in the poor category, respectively.

The results of this study could be part of disaster mitigation measures to prevent the spread of measles $[1,29]$ in developing countries with a tropical climate. The mapping results could provide a classification of prone red areas based on the coverage of poor immunization status. Policy makers such as the Health Office could make preventive measures based on the results of the classification.

\section{Spatial datasets}

Spatial data sets are used to classify parameters that affect the spread of measles [8]. Spatial datasets consist of two components: spatial data and attribute data. Both become parameters to determine the classification of measles-prone areas based on immunization status coverage factors as in Table 1, including PD3I, epidemic, nutritional status, and infant immunization.

In each spatial datasets the weight value was given, to determine the level of importance/influence on the classification produced in each parameter criterion [30, 31], This weighting used the fuzzification process, consisting of fuzzy sets indicators in giving a level description in the classification results [32].

\section{Methods}

Decision-making systems that involve GIS spatial data could be completed with MADM that be able to carry out integration in managing spatial data and attribute data to perform spatial data analysis [33]. Analysis of spatial data in the discussion of this paper resulted from spatial data modeling. the spatial datasets described in Table 1 be used as baseline data to produce a classification of measles-prone areas based on immunization status coverage.

The process stages in spatial data modeling for classification of tropical disease prone areas based on immunization status coverage were shown in the flowchart Fig. 1. This stage gave a picture of how the system works. Starting from inputting or recording of all data needs, then the process of modeling spatial data by determining the AI method that matches the behavior of the data obtained from the recording process, and the final process was to display the results of spatial data modeling in accordance with the functions and objectives to be achieved in GIS software development. 


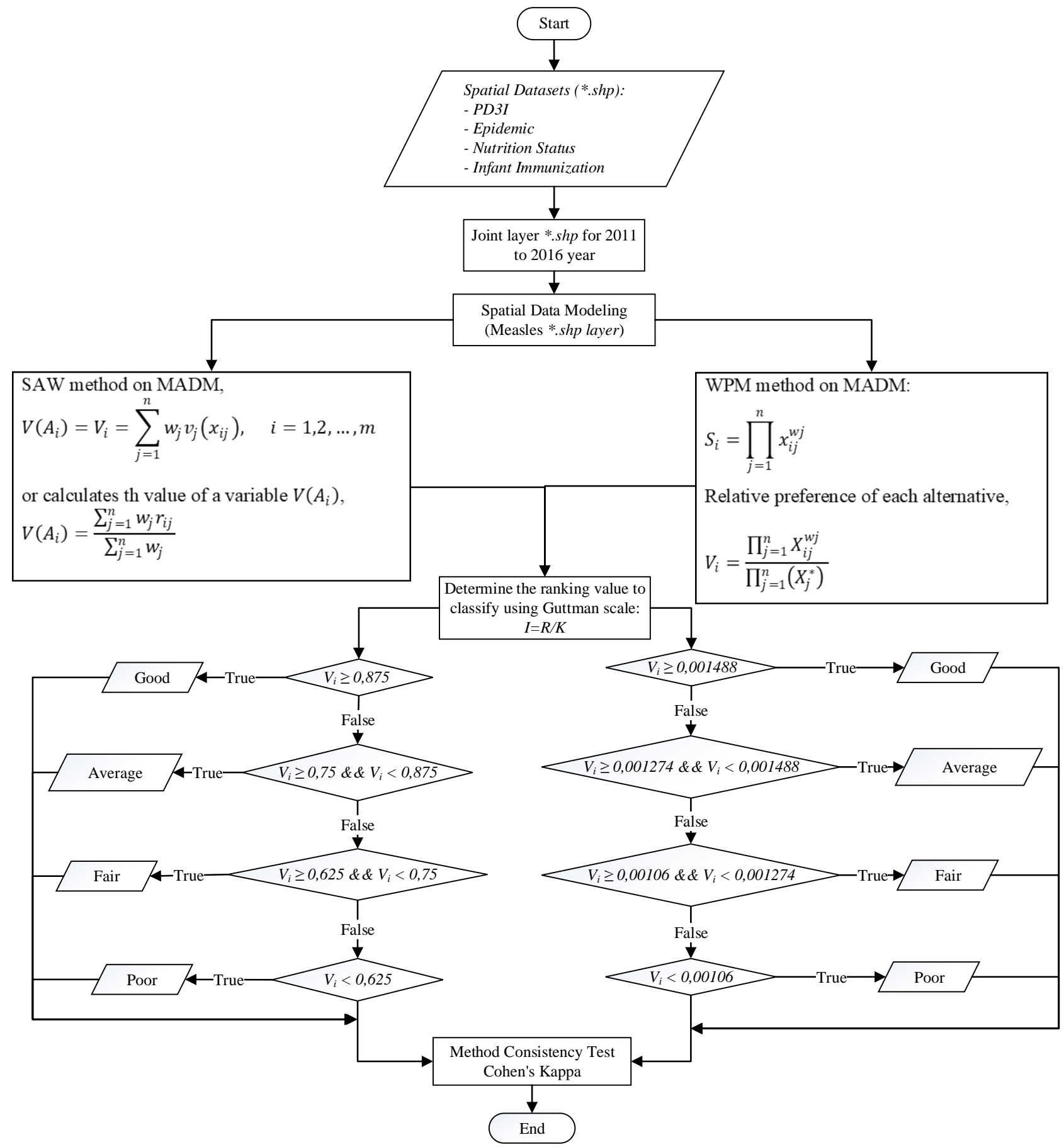

Figure. 1 Flow of spatial data modelling with SAW and WPM method

The first step, defining the spatial data requirements and layer attribute data in the spatial shapefile dataset $(* . s h p)$. The dataset includes a map of the East Java Province of Indonesia consisting of districts in each sub-district, including PD3I, epidemic, nutrition status, and infant immunization. The data used was qualitative [34] which was then cited [35] in each district with the concept of the overlay layer. This stage served to merge layers from 31 districts with data layers per sub-district to become a single layer.
The overlay layer results in one layer of measles (measles*.shp) for each year. This was called spatial interpolation. The SAW and the WPM method through the MADM method would process the results of the regulation's layer to get the preference value of $V i$. The Guttman method was used for classification of values with immunization status coverage categories with good, average, fair, and poor conditions in each sub-district.

The coverage of immunization status for the distribution of measles with the good category can be obtained if the $V_{i}$ value increases compared to the 
previous year. It can be concluded that the state of immunization status is reached or exceeded the target, indicated by the description of the green area. In regions with average immunization status coverage occurs if an area with immunization status reaches the minimum target which is represented by an area of orange color, where the value of $V_{i}$ falls from the condition of the previous year. It could be seen from the value of $V_{i}$ for the classification of regional categories with good immunization status. Fair classification occurs if in a region the value of $V_{i}$ falls compared to the previous year in the area with the average category. This happened because the immunization target did not reach the minimum target with an orange description of the area. Regions with a $V_{i}$ value below the average condition of good, average, and fair immunization status coverage, where the immunization target was not achieved, by mapping the red area.

\subsection{Multiple attribute decision making (MADM)}

MADM is part of the Multi-criteria decision making (MCDM) decision-making system, as well as multi-objective decision making (MODM) [36]. MODM was used for decision making that be sustainable, as in computing programming [37]. MADM and MCDM were used for discrete retrieval, where the alternative of the support system of the decision was predetermined [37].

The Simple Additive Weighting Method (SAW) and the Weight Product Model (WPM) method is part of a decision-making system using multi-parameter criteria with a multiple attribute decision making (MADM) approach [38]. MADM describes the parameters/criteria that will be used to determine the best alternative based on several appropriate criteria, the characteristics of decision making using the MADM system will describe the attribute requirements in the spatial analysis process, make the decision weight from the data that has been described Table 1 to form a decision matrix produced [37, 39, 40].

Approach to the SAW method by giving a score on each alternative produced to be multiplied by the value weight for each parameter attribute [41], with the following steps:

1. The SAW method produces the final value of $V_{i}$ in the Eq. (1) to obtain an alternative value from the classification that will be generated in the decision-making system [40].

$$
V\left(A_{i}\right)=V_{i}=\sum_{j=1}^{n} w_{j} v_{j}\left(x_{i j}\right), \quad i=1,2, \ldots, m
$$

where $V\left(A_{i}\right)=V_{i}$ is the alternative result value in the classification generated in each attribute $A_{i}$, this value is obtained from the calculation of the preference value $v_{j}\left(x_{i j}\right)$ on $V\left(A_{i}\right)$ and the $w_{j}$ weight in each parameter. The value of $V\left(A_{i}\right)$ can also be calculated using Eq. (2), where $r_{i j}$ is normalization from the calculation of the maximum value of the data on the parameter attribute.

$$
V\left(A_{i}\right)=\frac{\sum_{j=1}^{n} w_{j} r_{i j}}{\sum_{j=1}^{n} w_{j}}
$$

2. Calculating the preference value $v_{j}\left(x_{i j}\right)$ on $V\left(A_{i}\right)$ for each parameter attribute by finding the maximum value in each parameter attribute value using Eq. (3) and normalizing the maximum value obtained using the Eq. (4) [40].

$$
\max =\max \left(A_{i j}\right)
$$

where, the max value $\left(A_{i j}\right)$ is obtained from the parameter attribute, in this paper the parameter attribute value is described in Table 1 with the process on the spatial data input data $*_{\text {.sh }} p$ as described in Fig. 1 which refers to Eq. (4).

$$
\begin{aligned}
& \max \left(a_{i}\right)=\max \left(a_{i j}\right) \\
& \max \left(b_{i}\right)=\max \left(b_{i j}\right) \\
& \max \left(c_{i}\right)=\max \left(c_{i j}\right) \\
& \max \left(d_{i}\right)=\max \left(d_{i j}\right)
\end{aligned}
$$

where, to declare parameter attributes *.shp spatial dataset on all data $a_{i j}, \max \left(a_{i}\right)$ for PD3I, $\max \left(b_{i}\right)$ for epidemic, $\max \left(c_{i}\right)$ for nutritional status, and $\max \left(d_{i}\right)$ for infant immunization.

Normalize the value of each parameter attribute using Eq. (5), where $X_{j}$ is the data value that is $j$ and max is the value obtained from the calculation in Eq. (3) [40].

$$
r_{i j}=X_{j} / \max
$$

In this spatial data modeling, normalization values refer to Eq. (5) with the implementation of spatial datasets using Eq. (6).

$$
\begin{aligned}
& r\left(a_{i}\right)=\frac{a_{i}}{\max \left(a_{i j}\right)} ; r\left(b_{i}\right)=\frac{b_{i}}{\max \left(b_{i j}\right)} \\
& r\left(c_{i}\right)=\frac{c_{i}}{\max \left(c_{i j}\right)} ; r\left(d_{i}\right)=\frac{d_{i}}{\max \left(d_{i j}\right)}
\end{aligned}
$$

3. Calculates the preference value $v_{j}\left(x_{i j}\right)$ on $V\left(A_{i}\right)$ for all parameter attributes using Eq. (7) [40]. 


$$
V_{i}=\sum_{j=1}^{n} w_{j} r_{i j}, \quad i=1,2, \ldots, m
$$

where, $w_{j}$ is the weight of the parameter attribute value and $r_{i j}$ is the normalization value obtained in Eq. (5). The discussion in the trial in this paper uses Eq. (8) based on a literature study on Eq. (7).

$$
\begin{aligned}
& v\left(a_{i}\right)=\operatorname{Norm}\left(a_{i}\right) x \text { weight }\left(a_{i}\right) \\
& v\left(b_{i}\right)=\operatorname{Norm}\left(b_{i}\right) x \text { weight }\left(b_{i}\right) \\
& v\left(c_{i}\right)=\operatorname{Norm}\left(c_{i}\right) \times \text { weight }\left(c_{i}\right) \\
& v\left(d_{i}\right)=\operatorname{Norm}\left(d_{i}\right) x \text { weight }\left(d_{i}\right) \\
& V_{i}=v\left(a_{i}\right)+v\left(b_{i}\right)+v\left(c_{i}\right)+v\left(d_{i}\right)
\end{aligned}
$$

Approach to the WPM method use multiplication to connect the attribute rating. rating each attribute must be raised first with the weight of the attribute $[37,42]$. The steps of the WPM method normalize to find out the alternative preferences of $A_{i}$ in $S_{i}$ vectors, according to Eq. (9) [37, 42].

$$
S_{i}=\prod_{j=1}^{n} x_{i j}^{w j}
$$

where, $S$ variable is an alternative preference and is defined as a vector. $X_{i j}$ variable is the variable value from the alternative on each attribute. The criteria or sub-criteria weight values are accommodated in the $W_{j}$ variable. The $N$ variable is used to represent the number of criteria in the multi-criteria parameters declared. Variable $\mathrm{i}$ is the desired alternative value, and variable $j$ is the criteria value in the data. The value of the $\sum W_{j}$ variable is 1 with the rank positive for the profit attribute, and negative for the cost attribute. The relative preference of each alternative is calculated using Eq. (10) [37, 42].

$$
V_{i}=\frac{\prod_{j=1}^{n} X_{i j}^{w j}}{\prod_{j=1}^{n}\left(X_{j}^{*}\right)}
$$

where, $V_{i}$ variable is an alternative preference defined as a vector with $i$-th data. Determine the weight value for each parameter used to set the priority value on the existing parameters that are accommodated in the Bpre variable, do the sum for all priority values Tbpre $=$ Bpre $_{a}+$ Bpre $_{b}+\ldots n$. Calculating the value of variable $W$, with the weight value in variable $B$ divided by the number of values of the overall priority weight $W=B_{A} / \mathrm{Tb}$. Calculating the value of the variable $S$ on each weight value in variable $B$ is raised by the result of the variable $W$, with $S=B_{a} \wedge \mathrm{W}_{\text {a. }}$ Calculating the value of $V_{s}$ by multiplying all values in variable $S$, with $V_{s}=S_{a} x S_{b} x \ldots n$. calculating the total vector on variable $V$ or $T v_{s}$ by adding up all the values of $V_{s}$, with $T v_{s}=V_{1}+V_{2}+V_{3}+\ldots+V_{n}$, then the variable value of $V=V_{s a} / T v_{s a}$.

\subsection{The Guttman scale}

Measurement of the classification values generated in this paper uses the Guttman scale [43], This scale is the basis of measurement to draw conclusions on qualitative data [44], and is used to provide an estimate of the value of the classification results in an intervention value that is still ambiguous because of uncertainty [45]. In the type of dataset that uses a score/weight in the analysis process, provides a value based on the uncertainty factor of the variable class described, it can be measured using the Guttman scale [46] in the Eq. (11).

$$
I=\frac{R}{K}
$$

where $I$ is the result of the interval value obtained from the variable $R$, is the range of data values and variable $K$ with the number of alternative classifications that will be generated.

In the discussion of this paper, the variable value $R$ is obtained from the range of values between the maximum value of $V_{i}$ and the minimum value of $V_{i}$. The $K$ variable is the number of alternative classifications namely good, average, fair, and poor which refers to flow Fig. 1 and Table 2. Whereas, the determination of the scale for determining the classification value criteria for measles-prone areas based on the status of immunization coverage using Eq. (12) with SAW method and WPM method using Eq. (13).

$$
\begin{gathered}
\left\{\begin{array}{c}
\text { good, if } V_{i} \geq 0,875 \\
\text { average, if } V_{i} \geq 0,75 \text { and } V_{i}<0,875 \\
\text { fair, if } V_{i} \geq 0,625 \text { and } V_{i}<0,75 \\
\text { poor, if } V_{i}<0,625
\end{array}\right. \\
\left\{\begin{array}{c}
\text { good, if } V_{i} \geq 0,001488 \\
\text { average, if } V_{i} \geq 0,001274 \text { and } V_{i}<0,001488 \\
\text { fair, if } V_{i} \geq 0,00106 \text { and } V_{i}<0,001274 \\
\text { poor, if } V_{i}<0,00106
\end{array}\right.
\end{gathered}
$$


Table 2. The Guttman scale assessment

\begin{tabular}{|c|c|}
\hline SAW Method & WPM Method \\
\hline $\begin{array}{l}R=V_{i_{\text {maks }}}-V_{i_{\text {min }}}=1-0,5=0,5 \\
K=4 \\
I=\frac{0,5}{4}=0,125\end{array}$ & $\begin{array}{l}R=V_{i_{\text {maks }}}-V_{i_{\text {min }}}=0,001702-0,000846=0,000856 \\
K=4 \\
I=\frac{0,000856}{4}=0,000214\end{array}$ \\
\hline $\begin{array}{l}\text { Assessment good criteria } \\
\quad=\text { highest score }-I \\
\quad=1-0,125=0,875\end{array}$ & $\begin{array}{l}\text { Assessment good criteria } \\
\quad=\text { highest score }-I \\
\quad=0,001702-0,000214=0,001488\end{array}$ \\
\hline $\begin{array}{l}\text { Assessment average criteria } \\
\quad=\text { assesment good criteria }-I \\
\quad=0,875-0,125=0,75\end{array}$ & $\begin{array}{l}\text { Assessment average criteria } \\
\quad=\text { assesment good criteria }-I \\
\quad=0,001488-0,000214=0,001274\end{array}$ \\
\hline $\begin{array}{l}\text { Assessment fair criteria } \\
\quad=\text { assesment average criteria }-I \\
\quad=0,75-0,125=0,625\end{array}$ & $\begin{array}{l}\text { Assessment fair criteria } \\
\quad=\text { assesment average criteria }-I \\
\quad=0,001274-0,000214=0,00106\end{array}$ \\
\hline $\begin{array}{l}\text { Assessment poor criteria } \\
\quad=\text { assesment fair criteria }-I \\
\quad=0,625-0,125=0,5\end{array}$ & $\begin{array}{l}\text { Assessment poor criteria } \\
\quad=\text { assesment fair criteria }-I \\
\quad=0,00106-0,000214=0,000846\end{array}$ \\
\hline
\end{tabular}

\subsection{Method consistency test (MCT)}

Method Consistency Test Cohen's Kappa is used to test consistency in measuring two methods, this measurement can be done for qualitative data based Eq. (14) [47].

$$
K=\frac{\operatorname{Pr}(a)-\operatorname{Pr}(e)}{1-\operatorname{Pr}(e)}
$$

where, the variable $\mathrm{K}$ is the coefficient of the results of the measurement between methods. The variable $\operatorname{Pr}(a)$ is the percentage of the number of measurements that are consistent in making comparisons between methods, and the variable $\operatorname{Pr}(e)$ is the percentage change.

Range of coefficient values in variable $K$ [47], where if the variable value $K<20$, the value $K 0,21$ to 0,40 , the value $K$ is 0,41 to 0,60 , the value $K=0,61$ to 0,80 , dan $K 0,81$ to 1,00 , then strength of agreement are poor, fair, moderate, good, and very good, respectively.

\section{Results and discussion}

From the results of trials that have been carried out in 657 sub-districts in 38 regencies in 2011-2016 data obtained from the East Java Provincial Health Office of Indonesia [22-27]. The results of the modeling spatial data on the number of districts with categories of classification of measles-prone areas based on the status of immunization coverage with MADM in the SAW method as in Table 3, Fig. 2 and WPM method as in Table 4, Fig.3.
Table 3. Distribution of mapping classification results with the SAW method

\begin{tabular}{|c|c|c|c|c|c|c|}
\hline \multirow{2}{*}{ Class } & \multicolumn{7}{|c|}{ Sub-District } \\
\cline { 2 - 7 } & 2011 & 2012 & 2013 & 2014 & 2015 & 2016 \\
\hline Good & 449 & 488 & 423 & 442 & 409 & 432 \\
\hline Average & 113 & 79 & 94 & 134 & 108 & 134 \\
\hline Fair & 82 & 56 & 117 & 69 & 125 & 77 \\
\hline Poor & 13 & 34 & 23 & 12 & 15 & 14 \\
\hline
\end{tabular}

Table 4. Distribution of mapping classification results with the WPM method

\begin{tabular}{|c|c|c|c|c|c|c|}
\hline \multirow{2}{*}{ Class } & \multicolumn{7}{|c|}{ Sub-District } \\
\cline { 2 - 7 } & 2011 & 2012 & 2013 & 2014 & 2015 & 2016 \\
\hline Good & 299 & 531 & 494 & 299 & 306 & 315 \\
\hline Average & 340 & 92 & 140 & 337 & 333 & 324 \\
\hline Fair & 12 & 7 & 13 & 8 & 5 & 5 \\
\hline Poor & 6 & 27 & 10 & 13 & 13 & 13 \\
\hline
\end{tabular}

The results of the SAW method in the area with more good categories were $66.5(15 \%)$ compared to the results of the WPM method. The area in the average category for the results of the WPM method is $58 \%$ greater than the results of the SAW method. Regions with a fair category have more than $90 \%$ of the results of the WMP method rather than the results of the SAW method, and more than $26 \%$ of the results of the SAW method for regions with the poor category rather than the results of the WPM method. 


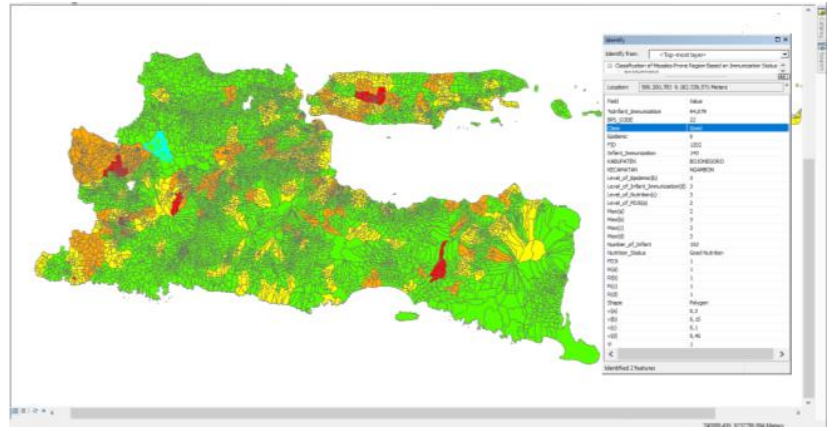

Figure. 2 The results of the MADM classification with the SAW method

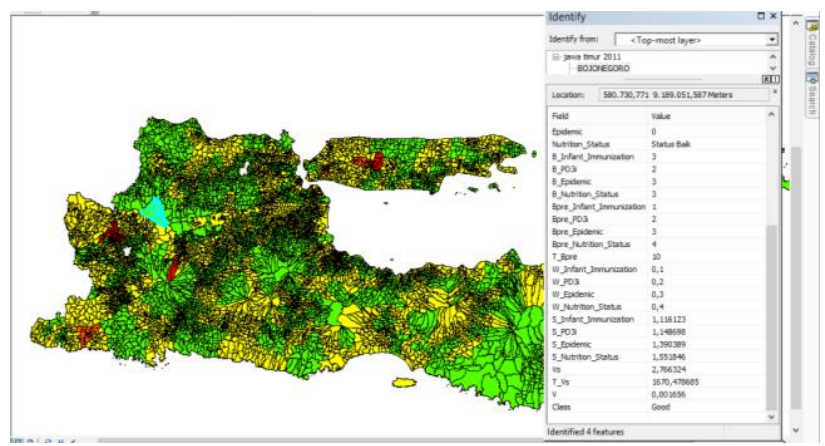

Figure. 3 The results of the MADM classification with the WPM method

The Results of the MADM Classification with the SAW Method in Fig.2. The layer value of datasets PD3I is 1 incidence rate (annually) to months a year, epidemic is 0 annually to months a year, nutrition status is good, and number of infant $=152$ infants with infant in immunization status is 143 infant for $94,079 \%$ infant immunization status, based on the level of importance referring to Table 1 , the values are 2, 3, 3, and 3, so $a=2 ; b=3 ; c=3 ; d=3$, to get the max value in Eq. (3), the data input process is carried out based on Eq. (4), namely: $\max \left(a_{i}\right)=$ $2 ; \max \left(b_{i}\right)=3 ; \max \left(c_{i}\right)=3 ; \max \left(d_{i}\right)=3$.

Normalization of the max value based on the theory in Eq. (5), the normalized value is obtained by dividing the value of the parameter variable with the max value of each variable referring to Eq. (6), namely: $r\left(a_{i}\right)=\frac{2}{2}=1 ; r\left(b_{i}\right)=\frac{3}{3}=1 ; r\left(c_{i}\right)=$ $\frac{3}{3}=1 ; r\left(d_{i}\right)=\frac{3}{3}=1$.

The preference value is obtained from the reference in Eq. (7), which is multiplying between normalization value and weight in each parameter variable in Table 1 using Eq. (8).

$v\left(a_{i}\right)=1 * 0,30=0,3 ; v\left(b_{i}\right)=1 * 0,15=0,15$; $v\left(c_{i}\right)=1 * 0,10=0,1 ; v\left(d_{i}\right)=1 * 0,45=0,45$

Then, the final value of the preference is:

$$
\begin{aligned}
V_{i} & =v\left(a_{i}\right)+v\left(b_{i}\right)+v\left(c_{i}\right)+v\left(d_{i}\right) \\
& =0,3+0,15+0,1+0,45=1
\end{aligned}
$$

Based on Eq. (12) which refers to Eq. (11), the value of $V_{i}$ is 1 entered in the range of good classification category in the area with green mapping, where the value of $V_{i}$ is greater than 0.875 .

Testing with the WPM method is based on Eq. (9) and Eq. (10) on Fig. 3 is done on the same spatial datasets as the SAW method. Epidemic scores were 0 , PD3I was 1 , the category of nutrition status was good, and the number of infants in the Subdistrict was 152 infants with immunization status of 147 infants or $94,079 \%$ of infants with immunization status. The level of importance includes 3, 2, 3, and 3, respectively. The priority value for each parameter includes $2,3,4$, and 1 , respectively. The number of priority value in the $T b_{\text {Pre }}$ is 10 , where the weight value in the $W$ variable for each parameter is $0.2,0.3$, 0.4 , and 0.1 , respectively. Calculation of the value of Vector in the $\mathrm{S}$ variable for each parameter variable, namely is 1,390389, 1,148698, 1,551846, and 1,116123. $V_{s}$ variable value is obtained by multiplying all $T_{V}$ values is 1670,478685 , then the total $V_{s}$ obtained from all calculated data is 2,766324 . The value of vector $V$ by dividing the value of $V_{s}$ by the value of $T_{V s}$, then the value of $V$ is 0,001656 , based on Eq. (13) and flow on Fig. 1, then the classification of regions with good categories

The test results using Cohen's Kappa for the feasibility of using the SAW method and the WPM method for modeling spatial data on GIS for classification of measles-prone areas using MADM, obtained kappa coefficients from the $\mathrm{K}$ variable -0.42 , $0,67, \quad 0,519367011, \quad 0,15, \quad 0,215627097$, and 0,253130142 for 2011-2016, respectively.

\section{Conclusion}

This paper examines the MADM technique in classifying multi-criteria parameters to produce spatial data modeling in its spatial process. The methods in MADM allows the results of comparative mapping in accordance with the level of importance, weight, and order of priority given to each of the parameter's multi-criteria variables in providing spatial sensitivity analysis.

This study resulted in the preference value of $V_{i}$ in the SAW method and WPM method by considering quantitative data and the calculation of the Guttman scale classification parameter value scale, this matter becomes very important in the decision-making system as a step-in planning to provide classification in identifying areas affected by tropical diseases in measles-like the results in Eq. (12) and Eq. (13).

This finding provides a new direction for using the MADM technique with the SAW and WPM method as part of the planning for mitigation measures, this finding encourages further research to 
use other quantitative data to influence the results of spatial data modeling.

Regions that are classified as fair or poor are important for policymakers in the field of surveillance and immunization of the Health Office to take anticipatory steps as a form of mitigation measures [1] of disasters causing epidemics of measles. The results of this spatial data modeling answer the role of quantitative data types that can be used as a reference in displaying a mapping to produce a classification of vulnerable areas as part of decision making, for example providing understanding to communities in fair and poor categories to be more caring through self-awareness in order to immunize areas with high epidemics can be choked. This is important because prevention is not only the responsibility of the health sector, but the role of the socio-economic environment is also a driver of the spread of measles infectious diseases [7].

Based on the discussion on testing data with MTC, it was concluded that the SAW method and the WPM method can be used for time series data types in spatial data modeling that do not have measurement data in the field. Results from MTC have a moderate category strength of agreement for use in spatial data modeling on the GIS for classification of measles-prone regions using MADM. They have results that are not much different.

Further research that can be developed is by collaborating the MADM method and data mining classification methods such as naïve Bayesian or decision tree, this function is to determine the comparison of the results of the classification given in each type of method used. Comparing the results of the classification of each method to be tested the level of accuracy of the method used through the method induction test.

\section{Acknowledgments}

This paper is the result of an Institutional National Strategy Research funded by the Directorate of Research and Community Service-Indonesia Country. Directorate General of Strengthening Research and Development of the Indonesian Ministry of Research, Technology and Higher Education in accordance with the 2018 Fiscal Year Research Contract Number: 120 / SP2H / LT / DRPM / 2018, January 30, 2018.

\section{References}

[1] A. S. Bandyopadhyay and U. Bandy, "Emerging global epidemiology of measles and public health response to confirmed case in rhode island", Rhode Island Medical Journal, Vol. 96,
No. 2, pp. 41-4, 2013.

[2] O.A.Khan, W.Davenhall, M.Ali, C.CastilloSalgado, G.Vazquez-Prokopec, U.Kitron, R.J.Soares Magalhaes, and A.C.A.Clements, "Geographical information systems and tropical medicine", Annals of Tropical Medicine \& Parasitology, Vol. 104, No. 4, pp. 303-318, 2010.

[3] World Health Organization, "Global Measles and Rubella Update June 2018", World Health Organization, No. April, p. 6, 2017.

[4] B. T. G. N. Bhart, A. Djibo, M. J. Ferrari, R. F.Grais, A. J. Tatem, C. A. Mccabe, and O. N. Bjornstad, "Measles hotspots and epidemiological connectivity", Epidemiology and Infection, Vol. 138, No. 9, pp. 1308-1316, 2010.

[5] T. C. Bailey and A. C. Gatrell, Interactive Spatial Data Analysis. Vol. 413, Essex: Longman Scientific \& Technical, 1995.

[6] D. P. Albert, W. M. Gesler, and B.Levergood, Spatial Analysis, GIS, and Remote Sensing Applications in the Health Sciences. Taylor \& Francis e-Library, 2005.

[7] B. Zhu, Y. Fu, J. Liu, and Y. Mao, "Spatial distribution of 12 class B notifiable infectious diseases in China: A retrospective study", PLoS One, Vol. 13, No. 4, pp. 1-17, 2018.

[8] W. W. Murdoch and C. J. Briggs, "Spatial dynamics of measles epidemics", Trends in Ecology \& Evolution, Vol. 17, No. 9, pp. 399401, 2002.

[9] R. Varatharajan, G. Manogaran, M. K. Priyan, V. E. Balaş, and C. Barna, "Visual analysis of geospatial habitat suitability model based on inverse distance weighting with paired comparison analysis", Multimedia Tools and Applications, Vol. 77, No. 14, pp. 17573-17593, 2018.

[10] W. Laohasiriwong, N. Puttanapong, and A. Luenam, "A comparison of spatial heterogeneity with local cluster detection methods for chronic respiratory diseases in Thailand", F1000Research, Vol. 6, No. May, p. 1819, 2017.

[11] R. N. Parker and E. K. Asencio, GIS and Spatial Analysis for the Social Sciences. Coding, Mapping and Modeling. Routledge Taylor \& Francis Group, 2009.

[12] G. Patanè and M. Spagnuolo, "Heterogenous Spatial Data: Fusion, Modeling, and Analysis for GIS Applications", Synthesis Lectures on Visual Computing: Computer Graphics, Animation, Computational Photography, and Imaging, Vol. 8, No. 2. pp.1-155, 2016.

[13] B. P. Carlin, A. E. Gelfand, and S. Banerjee, 
Hierarchical Modeling and Analysis for Spatial Data, Chapman and Hall/CRC, 2014.

[14] A. A. Putra and R. Munir, "Implementation of Fuzzy Inference System in Children Skin Disease Diagnosis Application", In: Proc. of the 5th International Conference on Electrical Engineering and Informatics 2015, pp. 365-370, 2015.

[15] A. P. Idowu and B. I. Akhigbe, "Data Mining Techniques for Predicting Immunize-able Diseases: Nigeria as a Case Study", International Journal of Applied Information Systems, Vol. 5, No. 7, pp. 5-15, 2013.

[16] E. Del Fava, Z. Shkedy, A. Bechini, P. Bonanni, and P. Manfredi, "Towards measles elimination in Italy: Monitoring herd immunity by Bayesian mixture modelling of serological data", Epidemics, Vol. 4, No. 3, pp. 124-131, 2012.

[17] D. Ntirampeba, I. Neema, and L. N. Kazembe, "Modelling spatial patterns of misaligned disease data: An application on measles incidence in Namibia", Clinical Epidemiology and Global Health, Vol. 5, No. 4, pp. 190-195, 2017.

[18] A. B. Lawson and C. Rotejanaprasert, "Bayesian spatial modeling for the joint analysis of zoonosis between human and animal populations", Spatial Statistics, Vol. 27, 2018.

[19] K. M. Eccles and S. Bertazzon, "Applications of geographic information systems in public health: A geospatial approach to analyzing MMR immunization uptake in Alberta", Canadian Journal of Public Health, Vol. 106, No. 6, pp. e355-e361, 2015.

[20] M. F. Rivadeneira, S. L. Bassanesi, and S. C. Fuchs, "Socioeconomic inequalities and measles immunization coverage in Ecuador: A spatial analysis", Vaccine, Vol. 36, No. 35, pp. 5251$5257,2018$.

[21] H. Luan and J. Law, "Web GIS-Based Public Health Surveillance Systems: A Systematic Review", ISPRS International Journal of GeoInformation, Vol. 3, No. 2, pp. 481-506, 2014.

[22] Dinas Kesehatan Provinsi Jawa Timur, Profil Kesehatan Provinsi Jawa Timur Th 2011. Dinas Kesehatan Provinsi Jawa Timur, 2012.

[23] Dinas Kesehatan Provinsi Jawa Timur, Profil Kesehatan Provinsi Jawa Timur Tahun 2012. Dinas Kesehatan Provinsi Jawa Timur, 2013.

[24] D. K. P. J. Timur, Profil Kesehatan Provinsi Jawa Timur 2013. Dinas Kesehatan Provinsi Jawa Timur, 2014.

[25] Dinas Kesehatan Provinsi Jawa Timur, Profil Kesehatan Provinsi Jawa Timur 2014. Dinas Kesehatan Provinsi Jawa Timur, 2015.
[26] Dinas Kesehatan Provinsi Jawa Timur, Profil Kesehatan Provinsi Jawa Timur 2015. Dinas Kesehatan Provinsi Jawa Timur, 2015.

[27] Dinas Kesehatan Provinsi Jawa Timur, Profil Kesehatan Provinsi Jawa Timur Tahun 2016. Dinas Kesehatan Provinsi Jawa Timur, 2017.

[28] A. V. Vitianingsih, D. Cahyono, and A. Choiron, "Analysis and design of web-geographic information system for tropical diseases-prone areas: A case study of East Java Province, Indonesia", In: Proc. of 2017 4th International Conference on Information Technology, Computer, and Electrical Engineering, pp. 255260, 2017.

[29] D. Engels, "The Global Trachoma Mapping Project: A Catalyst for Progress Against Neglected Tropical Diseases", Ophthalmic Epidemiology, Vol. 23, No. 1, pp. 1-2, 2016.

[30] R. R. Yager, "Categorization in multi-criteria decision making", Information Sciences, Vol. 460, pp. 416-423, 2017.

[31] S. A. Solovyov, "On fuzzification of topological categories" Fuzzy Sets Syst., Vol. 238, pp. 1-25, 2014.

[32] D. Sinha and E. R. Dougherty, "Fuzzification of set inclusion: Theory and applications", Fuzzy Sets and Systems, Vol. 55, No. 1, pp. 15-42, 1993.

[33] S. Drobne and A. Lisec, "Multi-attribute decision analysis in GIS: Weighted linear combination and ordered weighted averaging", Informatica (Ljubljana), Vol. 33, No. 4, pp. 459-474, 2009.

[34] A. S. Fotheringham, C. Brundson, and M. Chalrton, Qualitative Geography: Perspectives on Spatial Data Analysis. The Sage handbook of qualitative geography, 2010.

[35] F. Wang, "Quantitative methods and applications in GIS", CRC Press, 2006.

[36] M. J. Zhang and J. X. Nan, "A compromise ratio ranking method of triangular intuitionistic fuzzy numbers and its application to MADM problems", Iranian Journal of Fuzzy Systems, Vol. 10, No. 6, pp. 21-37, 2013.

[37] E. Triantaphyllou, Multi-criteria decision making methods. In Multi-criteria decision making methods: A comparative study, Springer, Boston, MA, 2000.

[38] D. D. Siregar, D. Arisandi, A. Usman, D. Irwan, and R. Rahim, "Research of Simple MultiAttribute Rating Technique for Decision Support", Journal of Physics: Conference Series, Vol. 930, No. 1, 2017.

[39] V. Maliene, R. Dixon-Gough, and N. Malys, "Dispersion of relative importance values 
contributes to the ranking uncertainty:

Sensitivity analysis of Multiple Criteria Decision-Making methods", Applied Soft Computing, Vol. 67, pp. 286-298, 2018.

[40] C. Kahraman, "Fuzzy Multi-Criteria Decision Making", Springer Science \& Business Media, Vol. 16, 2008.

[41] E. Celik, M. Gul, N. Aydin, A. T. Gumus, and A. F. Guneri, "A comprehensive review of multi criteria decision making approaches based on interval type-2 fuzzy sets", Knowledge-Based Systems, Vol. 85, No. September, pp. 329-341, 2015.

[42] E. Mulliner, N. Malys, and V. Maliene, "Comparative analysis of MCDM methods for the assessment of sustainable housing affordability", Omega (United Kingdom), Vol. 59, pp. 146-156, 2016.

[43] S. Psychology, G. Thomson, and W. Ledermann, The Determinacy of Factor Score Matrices With Implications for Five Other Basic Problems of Common-Factor Theory, Vol. VIII, No. 2, 1955.

[44] L. Guttman, "A Basis for Scaling Qualitative Data", American sociological review, Vol. 9, No. 2, pp. 139-150, 1944.

[45] R. E. Tractenberg, F. Yumoto, P. S. Aisen, J. A. Kaye, and R. J. Mislevy, "Using the Guttman scale to define and estimate measurement error in items over time: The case of cognitive decline and the meaning of "points lost", PLoS One, Vol. 7, No. 2, 2012.

[46] A. Stegeman, "A new method for simultaneous estimation of the factor model parameters, factor scores, and unique parts", Computational Statistics \& Data Analysis, Vol. 99, pp. 189-203, 2016.

[47] C. M. W. R. Azen, Categorical Data Analysis for the Behavioral and Social Sciences, New York, NY 10016: Taylor \& Francis Group, 2011. 